\title{
Formação profissional e debate sobre a questão racial no curso de Serviço Social da UnB: percepção das/os formandas/os e egressas/os do curso
}

Professional training and debate on racial issues in the social work course at the University of Brasilia: perception of graduates and alumni

\author{
Dyana Helena de Souza* \\ Lucélia Luiz Pereira**
}

\begin{abstract}
Resumo - Este artigo tem como objetivo analisar em que medida a questão racial está presente na formação das/os estudantes no curso de Serviço Social da Universidade de Brasília a partir da percepção de 55 estudantes, analisada por meio de entrevista estruturada com 49 estudantes e de grupo focal realizado com 6 egressas/os do curso. A pesquisa é de natureza qualitativa realizada com base na perspectiva do pensamento decoIonial e do pensamento negro contemporâneo. As/os participantes da pesquisa consideram que a questão racial ocupa lugar marginal na formação do curso, muitas vezes invisibilizada no currículo. Assim, recomendase que o eixo da questão racial seja contemplado na formação de maneira transversal em todas as disciplinas.
\end{abstract}

Palavras-chave: questão racial; Serviço Social; formação profissional.

\begin{abstract}
This article aims to analyze to what extent the racial issue is present in the formation of students of the social work course at the University of Brasilia, from the perception of 55 students analyzed through structured interviews with 49 students and a focus group with six graduates. The research is qualitative in nature, based on the perspective of decolonial thinking and contemporary black thinking. Research participants consider that the racial issue is not given enough attention in the course formation, oftentimes not explicit in the curriculum. Thus, it is recommended that the crux of the racial issue be contemplated in the course across all subjects.
\end{abstract}

Keywords: racial issue; social work; professional training.

\footnotetext{
* Mestranda no Programa de Pós-Graduação em Saúde Coletiva da Universidade de Brasília. Graduação em Saúde Coletiva (2014) e em Serviço Social (2018) pela Universidade de Brasília. E-mail: dyana_4521@hotmail. com. ORCID: https://orcid.org/0000-0001-6050-3337.

** Doutorado em Ciências da Saúde (UnB). Professora Adjunta do Departamento de Serviço Social da Universidade de Brasília. E-mail: lucelia@unb.br. ORCID: https://orcid.org/0000-0001-9722-143X.
} 


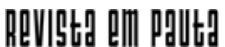

\} FORMAÇÃO PROFISSIONAL E DEBATE - SOUZA, D. H.; PEREIRA, L. L. \}

DOI: $10.12957 /$ REP.2020.47230

\section{Introdução}

Para estudar a formação da sociedade brasileira faz-se necessário desmistificar a democracia racial, pois ela utiliza um discurso da "junção/mistura" de vários povos, buscando justificar o argumento da inexistência do racismo no Brasil, uma vez que todos são o "mesmo povo" e têm o "mesmo sangue". Sabemos que esse mito mascara a essência racista da sociedade brasileira e que ainda fecha os olhos diante da discriminação racial (PEREIRA, 2016).

A branquitude se beneficiou da construção do mito da democracia racial, ignorando a dívida histórica que este país tem com a população negra e indígena. Invisibilizam o legado da Escravidão, negam os privilégios que a branquitude conquistou e permanece conquistando e justificam as políticas compensatórias ou de ação afirmativa como privilégio dos negros que querem se beneficiar sem "esforço e mérito" (BENTO, 2002). Portanto, a branquitude age de forma deliberada e atua com estratégias para manutenção da sua supremacia, como por exemplo a manutenção do racismo institucional. Sobre isso, Werneck (2016, p. 542) diz que o racismo institucional atua de forma a "induzir, manter e condicionar a organização e a ação do Estado, suas instituições e políticas públicas - atuando também nas instituições privadas produzindo e reproduzindo a hierarquia racial".

Portanto, a branquitude se considera um grupo padrão a ser seguido, ditando as regras que acabam "fortalecendo a autoestima e o autoconceito do grupo branco em detrimento dos demais, e essa apropriação acaba legitimando sua supremacia econômica, política e social" (BENTO, 2002, p. 5).

A partir dessa configuração, Ribeiro (2017, p. 48) considera que "os conhecimentos transmitidos nas universidades carregam a herança colonial e contribuem para reforçar a hegemonia cultural, econômica e política da modernidade/colonialidade". Dessa forma, "os saberes locais e, principalmente, aqueles que se originam de grupos subalternos, são excluídos do debate acadêmico, mantendo a colonialidade do saber, do ser e do poder" (RIBEIRO, 2017, p. 48). Após fazer crítica ao modo como as universidades estão organizadas, a autora sugere que:

Por isso, decolonizar a universidade é necessária para construir uma sociedade outra. Para decolonizar a universidade é preciso transdisciplinaridade, que não se limita a articular duas ou mais disciplinas, mas sim a considerar o terceiro elemento, ou seja, conectar os diversos elementos e formas de conhecimento. Diferentes formas culturais de conhecimento devem poder conviver no mesmo espaço universitário, sem o parcelamento do conhecimento e a recusa da experiência, da doxa. (RIBEIRO, 2017, p. 48).

É preciso refletir sobre a estrutura das universidades como espaços que reproduzem o pensamento do "sistema-mundo capitalista, patriarcal, 


\section{ReVIStg a d P P putt}

\} FORMAÇÃO PROFISSIONAL E DEBATE - SOUZA, D. H.; PEREIRA, L. L. \}

DOI: $10.12957 /$ REP.2020.47230

ocidental, cristão, moderno e colonialista" (COSTA; GROSFOGUEL, 2016, p. 31), mantendo um ensino fragmentado, hierarquizado e muitas vezes descontextualizado da realidade social. Destarte, as entidades representativas do Serviço Social necessitam estar em constante diálogo sobre o processo de formação profissional nas instituições de ensino superior.

No que se refere à questão racial, as entidades têm se posicionado a partir de documentos de domínio público, nos sites oficiais, e em congressos e encontros da categoria, tanto sobre aspectos relacionados à sua compreensão na sociedade brasileira quanto à necessidade de inserção da temática no ensino e na atuação profissional.

A Associação Brasileira de Ensino e Pesquisa em Serviço Social (ABEPSS, 2017 , p. 1) faz orientações sobre as cotas na pós-graduação, afirmando que "as políticas afirmativas devem desconstruir práticas que por séculos reproduzem o racismo institucional". Dessa forma, a nota disponibilizada demarca o posicionamento da entidade, assumindo o compromisso ético-político e acadêmico-histórico "com a defesa da superação de todas as formas de exploração e opressões", afirmando que a questão étnico-racial não deve ser "desvinculada dos processos de produção e reprodução da vida social" (ABEPSS, 2017, p. 1).

Destaca-se também uma importante iniciativa organizada pela Abepss (2018) de elaboração de documento intitulado Subsídios ao debate da questão étnico-racial na formação em Servic'o Social, construído coletivamente. O objetivo é oferecer elementos para o debate eitnico-racial no âmbito das unidades de formação da graduação, pós-graduação e nos espaços de educação permanente. $\mathrm{O}$ documento traz elementos que contribuem tanto para o fortalecimento da discussão do eixo na formação profissional como também para ampliar ações de combate ao racismo.

O Conselho Federal de Serviço Social (CFESS) tem criado uma série de campanhas e cadernos educativos sobre a atuação da/o assistente social no combate ao preconceito e às discriminações. Um desses cadernos contextualiza o racismo na história brasileira, bem como os seus reflexos na vida social da população negra e indígena. Situando a luta contra o racismo como uma exigência ética e política para a atuação profissional, o caderno aponta ainda "que contribui para o enfrentamento da desigualdade e da barbárie produzidas pela sociabilidade burguesa" (CFESS, 2016, p. 9). Além disso, em algumas edições do CFESS Manifesta (CFESS, 2011, 2013), a entidade trouxe seu posicionamento frente à questão racial, reforçando a necessidade de a categoria profissional se envolver em questões de combate ao racismo, considerando a "perspectiva da defesa dos direitos humanos e da luta para desvelar que é uma falácia a existência da democracia racial no Brasil" (CFESS, 2011, p. 243).

É importante destacar, ainda, a contribuição dos dois eventos centrais do Serviço Social, nos quais são apresentados trabalhos de docentes, estudantes e profissionais. São eles: Encontro Nacional de Pesquisadores 


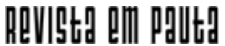

\} FORMAÇÃO PROFISSIONAL E DEBATE - SOUZA, D. H.; PEREIRA, L. L. \}

DOI: $10.12957 /$ REP.2020.47230

em Serviço Social (Enpess) e Congresso Brasileiro de Assistentes Sociais (CBAS). Ramos (2016, p. 58) estudou as edições dos dois eventos para analisar "os temas referentes à questão racial para abordar como a discussão temática tem sido feita na e para a categoria". A autora observou que a questão racial é um subtema encontrado nos eixos que "unem a questão racial à questão de gênero, orientação sexual e/ou geração" (RAMOS, 2016, p. 62). No Enpess, essa questão está incluída no eixo "Serviço Social, relações de exploração/ opressão de gênero, raça/etnia, geração, sexualidades"; no CBAS, no eixo "raça, etnia, gênero e sexualidades".

Apesar da relevância que os eixos têm, a autora identificou que nos trabalhos analisados "a questão racial é situada como recorte dos temas gerais" (RAMOS, 2016, p. 63), reduzindo o racismo ao estudo do negro, quando mais uma vez o torna objeto de estudo.

A denúncia do racismo reduzido ao estudo do negro limita a luta antirracista a uma luta que permanece na defensiva: ela se volta para o negro, enquanto aquilo que lhe imputa este lugar subalterno, permanece ileso na dicotomia racial: o branco. O problema racial é a branquitude. Esta quem deve ser estudada, desvelada e posta em xeque. (RAMOS, 2016, p. 63).

A autora afirma que os trabalhos ligados à temática refletem as reivindicações dos movimentos negros, sendo essenciais para embasar e direcionar uma prática profissional qualificada e que "venha a compreender as condições limitadoras e conflituosas que perpassem a realidade dos negros e negras no Brasil" (RAMOS, 2016, p. 64).

A página oficial da Executiva Nacional dos Estudantes de Serviço Social (ENESSO, 2014) também disponibiliza alguns materiais, como por exemplo a cartilha A quem serve o teu conhecimento?, resgatando o racismo, sua trajetória histórica, social e econômica brasileira, com destaque para a necessidade de reparação por meio de políticas públicas de combate às desigualdades e discriminação racial. No documento, foram abordadas as cotas raciais para implicar "numa igualdade de oportunidade para a população negra do país", e sobre como elas devem estar alinhadas a um novo projeto de sociedade (ENESSO, 2014, p. 6).

No Caderno de deliberações de 2015, a questão racial aparece em alguns momentos. Na conjuntura, ela aparece quando reconhecem que o Movimento Estudantil do Serviço Social (Mess) deve continuar na luta por uma (ENESSO, 2015, p. 4) "sociedade livre, igualitária contra a intolerância religiosa, sem exploração e opressão de classe, gênero, étnico-racial, orientação sexual e demais opressões e explorações". No que se refere ao combate às opressões, afirmam que a Enesso deve dar continuidade à discussão da questão racial em todos os fóruns do Mess. Trazem também a constante luta da Enesso $(2015$, p. 17) para "a implementação de disciplinas obrigatórias referentes à questão étnico-racial, gênero e sexualidade no currículo de serviço social". 


\section{ReVIStg a d P p puttg}

\} FORMAÇÃO PROFISSIONAL E DEBATE - SOUZA, D. H.; PEREIRA, L. L. \}

DOI: $10.12957 /$ REP.2020.47230

A pesquisa ora apresentada foi realizada na Universidade de Brasília (UnB), pioneira na implementação das cotas étnico-raciais no Brasil. $\mathrm{Na}$ UnB, o sistema de cotas foi implementado em 2004, enegrecendo esse espaço historicamente elitizado e branco. Sobre esse assunto, Carvalho (2018, p. 79) fala sobre "dois movimentos de descolonização do padrão racista e eurocêntrico do nosso mundo acadêmico que surgiram na Universidade de Brasília na década passada e dela se estenderam para as demais universidades": as cotas étnico-raciais, aprovadas pela Lei $n^{\circ} 12.711$, e o Encontro de Saberes, "que promove a inclusão de mestres e mestras dos nosso povos tradicionais como professores das universidades em matérias regulares" (CARVALHO, 2018, p. 80). Sendo assim, o autor defende:

a centralidade da instituição universitária nas lutas pela construção de um Estado brasileiro descolonizado e que seja de fato democrático e igualitário na sua justiça e no acesso aos recursos materiais, plurinacional, com equidade na sua diversidade étnica e racial, e deveres pluricultural e pluriepistêmico. (CARVALHO, 2018, p. 80).

Desta forma, o presente artigo, resultado de monografia apresentada como Trabalho de Conclusão de Curso, tem como objetivo analisar como o debate da questão racial está presente na formação do curso de Serviço Social da Universidade de Brasília (UnB), a partir da percepção das/ os formandas/os e de egressas/os do curso.

\section{Procedimentos metodológicos}

A pesquisa é de natureza qualitativa (MINAYO, 2006), realizada a partir da perspectiva do pensamento decolonial e do pensamento negro contemporâneo (SILVA; SANTIAGO, 2016; REIS; ANDRADE, 2018). A investigação foi realizada no ano de 2018 e teve 55 participantes, sendo composta por estudantes que cursavam as disciplinas de Projeto de Trabalho de Conclusão de Curso (PTCC) e de Trabalho de Conclusão de Curso (TCC), bem como de egressas/os do curso de Serviço Social que realizaram TCC sobre a questão racial.

Foram feitas entrevistas estruturadas com 49 estudantes de PTCC e de TCC, uma vez que esses já estavam nas etapas finais do curso, tendo concluído a maior parte das disciplinas do fluxo. As entrevistas foram realizadas a partir de instrumental contendo 24 questões pré-definidas relacionadas à caracterização do perfil das pessoas entrevistadas, bem como experiência com o debate da questão racial durante a formação. Além disso, realizou-se um grupo focal com seis egressas/os do curso, sendo que todas/ os abordaram a temática racial nos TCCs e se autodeclararam negras/os.

Para a condução do grupo focal, foi utilizado um roteiro contendo cinco questões que nortearam a condução do grupo e versaram sobre o in- 


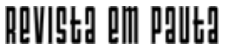

\} FORMAÇÃO PROFISSIONAL E DEBATE - SOUZA, D. H.; PEREIRA, L. L. \}

DOI: $10.12957 /$ REP.2020.47230

teresse e aproximação da temática racial durante a formação, as motivações para centralizar a temática racial na monografia e as dificuldades e desafios para a inserção do debate da questão racial durante a formação em Serviço Social. Optou-se por realizar o grupo focal pela compreensão de que tal técnica, como afirma Trad (2009, p. 1), "permite atender ao objetivo de apreender percepções, opiniões e sentimentos frente a um tema determinado", neste caso específico, a vivência de egressas/os do curso com o debate étnico-racial durante a formação.

Com relação aos aspectos éticos, informou-se aos participantes sobre os objetivos do estudo, de modo que assinaram o Termo de Consentimento Livre e Esclarecido (TCLE). Além disso, foram garantidos o anonimato e a não identificação durante a análise dos dados.

Como estratégia para análise dos resultados, adotou-se inicialmente a sistematização dos dados das entrevistas estruturadas e do grupo focal; posteriormente, utilizou-se a técnica de análise de conteúdo, a partir das etapas empregadas por Bardin (2010): pré-análise, exploração do material, tratamento e interpretação dos resultados, procedendo, assim, à sistematização e categorização das informações com base na literatura e focando os temas pertinentes ao estudo.

\section{Percepção das formandas/os e de egressas/os sobre a inserção do debate da questão racial na formação no curso de Serviço Social da UnB}

A média de idade das/os 55 estudantes que participaram da entrevista estruturada e do grupo focal foi de 25 anos. Com relação à identidade de gênero, 46 participantes se identificaram como mulheres cisgênero, uma como mulher transgênero e oito como homens cisgênero. Com relação à orientação sexual, 36 se identificaram como heterossexuais, 11 como bissexuais, quatro como lésbicas, três como gays e um marcou a categoria outros. A raça/cor das/os participantes contou com um perfil de 25 que se autodeclaram brancas/os, 19 como pardas/os, 11 como pretas/os e nenhuma/ nenhum se autodeclarou indígena. Apenas 12 informaram que entraram na universidade pelo sistema de cotas sociais e 7 informaram que entraram pelo sistema de cotas raciais.

Das/os 49 estudantes que participaram da entrevista estruturada, a maioria considerou que a questão racial deve ter espaço na formação da graduação em Serviço Social; 38 desconheciam a existência de grupos ou linhas de pesquisa no departamento sobre a questão racial; 37 consideraram que a categoria profissional contempla o debate de forma marginal e 32 afirmaram que o curso prepara parcialmente as/os estudantes para lidarem com as temáticas relacionadas a racismo e discriminação racial. 


\section{ReVIStg a d P p putt}

\} FORMAÇÃO PROFISSIONAL E DEBATE - SOUZA, D. H.; PEREIRA, L. L. \}

DOI: $10.12957 /$ REP.2020.47230

Foi unânime entre as/os participantes o reconhecimento de que o racismo não foi superado, o que dialoga com o referencial adotado neste trabalho (RAMOS, 2016; PEREIRA, 2016; BENTO, 2002). Também foi consenso que a formação em Serviço Social contempla de forma marginal a questão racial, o que pode ser observado no estudo de Marques Júnior (2007, p. 17), que verificou como esse debate tem sido incluído na formação, identificando "alguns desafios e limites postos a reflexão dentro do serviço social". Ele levantou algumas hipóteses sobre esses desafios, como: "a pouca quantidade de professores universitários do serviço social pesquisando sobre questão racial, a subalternidade dessa questão frente a outras ditas como prioritárias, e a ideologia da democracia racial presente no contexto nacional" (MARQUES JÚNIOR, 2007, p. 18).

Em estudo anterior, Silva Filho (2004, p. 107) constatou que estudantes formadas/os em Serviço Social pela Universidade Federal Fluminense (UFF) "não aprendem saberes sobre a questão racial do negro na nossa sociedade". Por meio de aplicação de questionários, o autor percebeu que "os temas sobre cultura, sobre a história e sobre as teorias raciais" não eram discutidos no curso (SILVA FILHO, 2004, p. 107). Ao analisar 1.347 TCCs, de 1947 a 2002, notou que apenas seis abordavam o tema. No período de realização da pesquisa, o autor verificou que o corpo docente entrevistado "não se encontra capacitado para fomentar discussões acerca desse tema" (SILVA FILHO, 2004, p. 108).

Confirmando a perpetuação dos dados pesquisados por Silva Filho (2004), as/os participantes da pesquisa mostraram o reconhecimento de que o Serviço Social dá maior ênfase para a questão de classe, o que pode ser evidenciado também por Ramos (2016, p. 49), ao trazer os três equívocos "nesta análise que atribuem a essa perspectiva classista um viés racista".

Nos dados das entrevistas estruturadas ficou evidente o desconhecimento de grupos ou linhas de pesquisa no Departamento de Serviço Social que fomentam debates sobre a questão racial. Nove participantes afirmaram conhecer algum grupo de pesquisa e citaram somente três docentes que têm feito o debate por meio desses mecanismos. Além disso, no grupo focal também foram mencionadas/os as/os mesmas/os professoras/es como coordenadoras/es desses grupos.

Os dados apontaram que surgiram demandas durante o período de estágio das/os estudantes em que elas/es perceberam situações relacionadas à discriminação racial, o que as/os motivou a aprofundar o tema durante a monografia, como relataram as/os participantes do grupo focal. Souza e Garcia (2017) mencionaram que a questão racial pouco tem sido desenvolvida nos espaços sócio-ocupacionais, ainda que exista a demanda. Por esse motivo, destacam a importância do estágio supervisionado nesse processo.

Os resultados alcançados pela pesquisa dialogam com a literatura, uma vez que as/os participantes consideraram que o curso de Serviço Social 


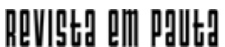

\} FORMAÇÃO PROFISSIONAL E DEBATE - SOUZA, D. H.; PEREIRA, L. L. \}

DOI: $10.12957 /$ REP.2020.47230

prepara os futuros profissionais parcialmente para lidarem com temáticas relacionadas a racismo e discriminação racial, o que já tem sido evidenciado em outros estudos, como afirma Dias (2015, p. 324):

\begin{abstract}
Entre outros motivos, alguns entraves se dão pela baixa produção teórica acerca desses temas, e também pela pouca apropriação da categoria pela discussão das temáticas de cor/raça/etnia. A discussão étnico-racial sempre foi secundarizada por essa categoria profissional, e por muitos profissionais não é percebida como importante variável para uma análise crítica das relações sociais sob a perspectiva de totalidade.
\end{abstract}

Silva (2015, p. 13) discutiu a temática no cotidiano profissional e percebeu a urgência de o serviço social aprofundar o debate, considerando que as/os profissionais, ao "se depararem com as diversas expressões da questão social, e não possuírem elementos que os coloquem no cerne desta discussão, [continuarão] a perpetuar como esta categoria (raça/etnia) vem sendo trabalhada de forma tão superficial".

Já nas entrevistas estruturadas, a maioria das/os participantes considerou que deve existir uma disciplina obrigatória no curso; no grupo focal, todas/os as/os participantes afirmaram que ela deve ser inserida em todos os conteúdos. Também foi observado que a disciplina Gênero, Raça/Etnia e Política Social, ofertada pelo curso como optativa, é uma referência entre as/os estudantes, mas a principal crítica é que a disciplina abarca os três eixos, tornando o debate superficial. Há a necessidade de que se tenha espaço na estrutura curricular para inserção da temática.

Rocha (2009) e Dias (2015) afirmam que há um desafio para inserção da questão étnico-racial na formação profissional e que este desafio está presente na materialização do Projeto Ético-Político (PEP).

Esta categoria profissional se coloca na luta pela afirmação de direitos dos usuários dos seus serviços, e se a questão racial também compõe o conjunto das relações sociais brasileiras, é urgente que tal debate ocupe o devido destaque na agenda e nos fóruns de formação profissional. É necessário também, que esta categoria assuma o compromisso político de debater outros assuntos que se interseccionam com a temática étnicoracial como classe, gênero, sexualidade e outros. (DIAS, 2015, p. 325).

Os resultados apontam a sinalização das/os participantes para o fato de que a categoria profissional contempla o debate de forma marginal. A articulação do conjunto das categorias é essencial para o fortalecimento do PEP (DIAS, 2015), sendo necessário que as "concepções teóricas que dão embasamento à temática sejam 'devidamente apropriadas' pela categoria, que também não estão isentas do discurso da democracia racial" (EURICO, 2011, p. 127).

Oliveira (2015, p. 97) analisou os projetos político-pedagógicos (PPP) e as matrizes curriculares de cursos de Serviço Social "que têm disci- 




\} FORMAÇÃO PROFISSIONAL E DEBATE - SOUZA, D. H.; PEREIRA, L. L. \}

DOI: $10.12957 /$ REP.2020.47230

plinas que trabalham as questões étnico-raciais no processo de formação profissional" e apontou que também é possível identificar nos currículos "as mesmas contradições existentes na sociedade". Ela ainda destacou que a questão social como é vista na formação tende a "negar e negligenciar as lutas sociais vividas e consolidadas pela população negra" (OLIVEIRA, 2015, p. 97). Ramos (2015, p. 98) também refletiu sobre essa questão:

Para tanto, acredito que esse hiato entre as bases teóricas da profissão e as requisições da população negra só pode ser superado, quando a categoria profissional redirecionar o seu processo de formação, implementando uma reestruturação curricular, que a reativação das discussões, ou melhor, a implementação dos objetivos formativos em torno dos conceitos descritos nos Parâmetros Curriculares Mínimos da ABEPSS, de 1996, e a reoxigenação das discussões do GT - 06 da mesma entidade, implementando normativas e recomendações acerca da consolidação dos temas elencados naquele eixo; fomentar a discussão nos âmbitos das IFES, com apoio das comissões temáticas de raça e etnia dos CRESS.

Conceição (2013) relembra que os núcleos essenciais para a formação que estão presentes nas diretrizes curriculares do curso (DCs) são: núcleo de fundamentos teórico-metodológicos da vida social, núcleo de fundamentos da formação sócio-histórica brasileira; e núcleo de fundamentos do trabalho profissional. Para a autora, esses núcleos formam a estrutura básica do conhecimento das/os assistentes sociais e é por meio deles que se percebe a necessidade de compreender a questão étnico-racial no Brasil.

Santos (2017) ressaltou que, ainda que seja um debate fundamental para compreensão da realidade social brasileira, a questão étnico-racial encontra-se ausente na matriz curricular, pois há forte influência de uma formação conservadora e eurocêntrica que prioriza o estudo das classes sociais. Assim, este trabalho faz uma crítica ao eurocentrismo, situando o Serviço Social nessa realidade, que ainda "apresenta um distanciamento para com os determinantes sócio-históricos da realidade em que se insere" (RAMOS, 2016, p. 75). Por fim, concordamos com a autora quando afirma que:

Esse movimento consequentemente acarretará na ampliação da produção de conhecimento da categoria sobre as dimensões raciais que estão presentes na Questão Social e na composição da classe dominante no Brasil. É, sobretudo, necessário que a temática seja inserida em todas as ementas. (RAMOS, 2016, p. 77).

Portanto, a questão racial brasileira não deve ser apagada da história e o Serviço Social deve fortalecer este debate tanto na formação quanto na atuação profissional. A ausência dessa discussão durante o processo formativo reflete-se no exercício profissional, podendo acarretar uma atuação que reproduz o racismo e não reconhece as necessidades e especificidades da população negra. 


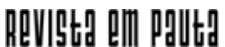

\} FORMAÇÃO PROFISSIONAL E DEBATE - SOUZA, D. H.; PEREIRA, L. L. \}

DOI: $10.12957 /$ REP.2020.47230

\section{Considerações finais}

A reflexão sobre a formação da questão racial brasileira possibilitou uma aproximação dos principais elementos que compõem as relações raciais no país, desmistificando a democracia racial que mantém os privilégios da branquitude. Inúmeras são as iniquidades vivenciadas pela população negra e que dificultam seu acesso às políticas públicas; por isso, os espaços institucionais devem ser tensionados, procurando-se questionar sua estrutura racista.

A formação profissional tem uma base comum em âmbito nacional, constituída de três núcleos de fundamentação, porém, constatou-se que a questão racial não tem sido inserida no núcleo de fundamentos da particularidade da formação sócio-histórica brasileira. Se a categoria profissional afirma que esses três núcleos são indissociáveis, como desconsiderar que a questão racial é basilar na sociedade brasileira?

lamamoto (2014, p. 629) afirmou que um dos desafios para o Serviço Social é "impulsionar estudos históricos sobre a formação sócio-histórica do Brasil e da América Latina, favorecendo estudos comparados", e essa é uma lacuna que precisa ser discutida de forma ampliada na formação. Nesse sentido, reafirma-se que a articulação entre as entidades representativas do Serviço Social deve ser constante, pois, apesar de se posicionarem afirmando uma consciência de classe antirracista, antipatriarcal e anti-heterossexista, há uma lacuna na formação das/dos estudantes, que consideram que a categoria aborda a questão racial parcialmente.

Foi possível observar que, mesmo com uma disciplina optativa que aborda especificamente o Serviço Social e as relações de exploração/ opressão de sexo/gênero, raça/etnia, geração e sexualidades, ela não tem sido suficiente. Isso porque há o entendimento de que esses temas devem estar articulados durante toda a formação, e não apenas em uma disciplina optativa. Geralmente, as/os estudantes que buscam a disciplina são aquelas/ es que já têm sensibilidade ao tema, mas o grande desafio é encontrar estratégias para aproximar esse tema das/os estudantes que não o veem como relevante na formação profissional.

Percebemos que a estrutura das universidades reproduz o pensamento capitalista, colonialista e patriarcal. Além disso, pautada nessa lógica, ela reúne homens com privilégio epistêmico, que desconsideram os conhecimentos que não estão no padrão de modernidade europeia. Porém, como afirma Ribeiro (2017), os movimentos sociais têm exercido um pensamento decolonial, afirmando sua identidade e ocupando espaços que foram negados e mostrando que há outras formas e visões para compreensão do mundo. Portanto, esses movimentos de resistência no Brasil têm contribuído para a valorização de saberes historicamente subalternizados.

O Serviço Social está situado na reprodução das relações sociais e atua em um universo antagônico, e sua ampliação e consolidação no 


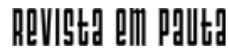

\} FORMAÇÃO PROFISSIONAL E DEBATE - SOUZA, D. H.; PEREIRA, L. L. \}

DOI: 10.12957/REP.2020.47230

Brasil acompanham o conjunto das transformações societárias. A sua consolidação definiu uma direção social orientadora do projeto profissional, e a materialização do Projeto Ético-Político se dá por meio do Código de Ética e da Lei de Regulamentação da Profissão: esses defendem a equidade e uma sociedade sem dominação, sem exploração de classe, de raça/etnia e de gênero. Destaca-se a equidade como princípio que deve nortear a formação das/os estudantes, bem como a atuação profissional, considerando o papel do Serviço Social no combate às desigualdades raciais e as possibilidades que a aproximação com a temática pode incidir nos espaços sócioocupacionais. 


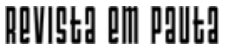

\} FORMAÇÃO PROFISSIONAL E DEBATE - SOUZA, D. H.; PEREIRA, L. L. \}

DOI: $10.12957 /$ REP.2020.47230

\section{Referências}

ABEPSS. Diretrizes gerais para o curso de Serviço Social. Rio de Janeiro: Abepss, 1996.

ABEPSS. As cotas na pós-graduação: orientações da Abepss para o avanço do debate. 2017. Disponível em: http://www.abepss.org.br/noticias/ ascotasnaposgraduacaoorientacoesdaabepssparaoavancododebate-97. Acesso em: 3 nov. 2017.

ABEPSS. Subsídios para o debate sobre a questão étnico-racial na formação em Serviço Social. 2018 Disponível em: http://www.abepss.org.br/arquivos/ anexos/subsidio_debate_uestao_etnico_servico_social-20181204 1419427146430.pdf. Acesso em: 10 maio 2019.

BARDIN, L. Análise de conteúdo. Lisboa: Edições 70, 2010.

BRASIL. Lei no 8.662 , de 7 de junho de 1993. Dispõe sobre a profissão de Assistente Social e dá outras providências. 1993. Disponível em http://www. planalto.gov.br/ccivil_03/leis/L8662.htm. Acesso em: 3 nov. 2017.

BENTO, M. A. S. Branqueamento e branquitude no Brasil. In: CARONE, I.; BENTO, M. B. S. (org.). Psicologia social do racismo - estudos sobre branquitude e branqueamento no Brasil. Petrópolis: Vozes, 2002.

CARVALHO, J. J. Encontro de saberes e cotas epistêmicas: um movimento de descolonização do mundo acadêmico brasileiro. In: BERNARDINOCOSTA, J.; MALDONADO TORRES, N.; GROSGOGUEL, R. (org.). Decolonialidade e pensamento afrodiaspórico. Belo Horizonte: Autêntica Editora, 2018.

COSTA, B. J.; GROSFOGUEL, R. Decolonialidade e perspectiva negra. Revista Sociedade e Estado, v. 31, n. 1, jan./abr. 2016.

CFESS. Código de ética do assistente social. Resolução CFESS, n. 273, 1993.

CFESS. CFESS manifesta. Brasília, maio 2011. Disponível em: http://www.c fess.org.br/arquivos/CFESSMANIFESTA_ATITUDECRITICA(2008-2011).pdf. Acesso em: 3 nov. 2017.

CFESS. Manifesto CFESS, Abepss, Enesso. Brasília, 2011. Disponível em: http://www.cfess.org.br/arquivos/cartaentidades_CFESS-ABEPSSENESSO_FINAL.pdf. Acesso em: 3 nov. 2017.

CFESS. CFESS Manifesta - Dia da Consciência Negra. Brasília, 20 nov. 2013. Disponível em: http://www.cfess.org.br/arquivos/2013cfessmanifesta _consciencianegra.pdf. Acesso em: 3 nov. 2017.

CFESS. Assistente social no combate ao preconceito-racismo. Brasília, 2016. 


\section{ReVIStg a d P p putt}

\} FORMAÇÃO PROFISSIONAL E DEBATE - SOUZA, D. H.; PEREIRA, L. L. \}

DOI: $10.12957 /$ REP.2020.47230

CONCEIÇÃO, R. M. A questão racial como expressão da questão social: um debate necessário para o Serviço Social. 2013. Monografia (Bacharelado em Serviço Social) -Universidade de Brasília, Brasília, 2013.

DIAS, S. A. Serviço Social e as relações raciais: caminhos para uma sociedade sem classes. Temporalis, ano 15, n. 29, jan./jun. 2015. Disponível em: http:/ /periodicos.ufes.br/temporalis/article/view/7182/7483. Acesso em: 18 maio 2018.

ENESSO. Que bicho é esse? 2014. Disponível em: https://enessooficial. files.wordpress.com/2014/04/cartilha-enesso-1.pdf. Acesso em: 3 nov. 2017.

ENESSO. A quem serve o teu conhecimento? 2014. Disponível em: https:// enessooficial.wordpress.com/enesso/materiais/. Acesso em: 3 nov. 2017.

ENESSO. Enesso feminista. 2013. Disponível em: https://enessooficial. wordpress.com/enesso/materiais/. Acesso em: 3 nov. 2017.

ENESSO. Caderno de deliberações. 2015. Disponível em: https://enesso oficial.files.wordpress.com/2011/06/caderno-de-deliberac3a7c3b5es2015.pdf. Acesso em: 3 nov. 2017.

EURICO, M. C. Questão racial e Serviço Social: uma reflexão sobre o racismo institucional e o trabalho do assistente social. 2011. 143 f. Dissertação (Mestrado em Ciências Sociais Aplicadas) - Pontifícia Universidade Católica de São Paulo, São Paulo, 2011.

IAMAMOTO, M. V. A formação acadêmico-profissional no Serviço Social brasileiro. Serviço Social e Sociedade, São Paulo, n. 120, out./dez. 2014.

MARQUES JÚNIOR, J. S. Questão racial e Serviço Social: um olhar sobre sua produção teórica antes e depois de Durban. Libertas, v. 13, n. 1, 2007. Disponível em: https://libertas.ufjf.emnuvens.com.br/libertas/article/view/ 2693/1949. Acesso em: 19 maio 2018.

MINAYO, M. C. S. O desafio do conhecimento: pesquisa qualitativa em saúde. São Paulo: Hucitec, 2006.

OLIVEIRA, J. M. S. A transversalidade da questão étnico-racial nos currículos dos cursos de graduação em Serviço Social das universidades federais brasileiras. 2015. 127f. Dissertação (Mestrado em Estudos Interdisciplinares sobre a Universidade) - Universidade Federal da Bahia, Bahia, 2015.

PEREIRA, L. L. Repercussões do Programa Mais Médicos em comunidades rurais e quilombolas. 2016. 250f. Tese (Doutorado em Ciências da Saúde) Universidade de Brasília, Brasília, 2016.

QUIJANO, A. Colonialidad del poder y clasificación social. In: CASTROGÓMEZ, S.; GROSFOGUEL, R. (org.). El giro decolonial: reflexiones para una diversidad epistémica mas allá del capitalismo global. Bogotá: Siglo del Hombre Editores, 2007. 


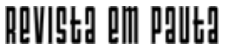

\} FORMAÇÃO PROFISSIONAL E DEBATE - SOUZA, D. H.; PEREIRA, L. L. \}

DOI: $10.12957 /$ REP.2020.47230

RAMOS, D. O. A branquitude como uma estrutura e a questão social negra no Brasil: a análise da produção científica do Serviço Social no Enpess e CBAS. Monografia (Bacharelado em Serviço Social) - Universidade de Brasília, 2016.

REIS, M. N.; ANDRADE, M. F. F. O pensamento decolonial: análise, desafios e perspectivas. Revista Espaço Acadêmico, v. 17, n. 202, 2018. Disponível em: http://periodicos.uem.br/ojs/index.php/EspacoAcademico/article/view/ 41070. Acesso em: 11 jul. 2018.

RIBEIRO, D. Decololizar a educação é possível? A resposta é sim e ela aponta para a educação quilombola. Identidade, v. 22 n. 1, jan./jul. 2017. Disponível em: http://educere.bruc.com.br/arquivo/pdf2017/23612_11891.pdf. Acesso em: 18 maio 2018.

ROCHA, R. F. A questão étnico-racial no processo deformação em Serviço Social. Serviço social e Sociedade, São Paulo, n. 99, jul./set. 2009.

SANTOS, F. S. A população negra e a formação profissional em Serviço Social da Universidade Federal de Santa Catarina: questão racial no projeto político pedagógico, a grande ausência. 2017. 82f. Monografia (Bacharelado em Serviço Social) - Universidade Federal de Santa Catarina, 2017. Disponível em: https://repositorio.ufsc.br/handle/123456789/175266. Acesso em: 20 maio 2018.

SILVA FILHO, J. B. A questão do negro no curso de graduação de Serviço Social da Universidade Federal Fluminense. 2004. 128f. Dissertação (Mestrado em Política Social) - UFF, Niterói, 2004. Disponível em: http:// www.bdtd.ndc.uff.br/tde_arquivos/22/TDE-2006-08-01T121544Z-242/Publi co/PolitcaSocial-Dissert-JoseSilva.pdf. Acesso em: 1 maio 2018.

SILVA, C.; SANTIAGO, E. Pensamento negro e educação intercultural no Brasil. Revista Interritórios, v. 2, n. 3, 2016. Disponível em: https://periodicos.ufpe.br/revistas/interritorios/article/view/8691/0. Acesso em: 11 jul. 2018.

SILVA, R. O. Categoria raça/etnia, Serviço Social e formação profissional: um debate urgente. In: ENCONTRO INTERNACIONAL DE POLÍTICA SOCIAL, 3; ENCONTRO NACIONAL DE POLÍTICA SOCIAL, 10. Anais [...]. 2015. Disponível em: http://periodicos.ufes.br/EINPS/article/view/9960. Acesso em: 18 maio 2018.

SOUZA, D. H.; GARCIA, A. M. Questão racial e Serviço Social: relato de experiência do estágio supervisionado. In: SEMINÁRIO NACIONAL DE SERVIÇO SOCIAL, TRABALHO E POLÍTICA SOCIAL, 2. Anais [...]. Florianópolis, 2017. Disponível em: https://repositorio.ufsc.br/handle/123456789/180016. Acesso em: 18 maio 2018. 


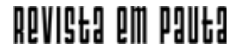

\} FORMAÇÃO PROFISSIONAL E DEBATE - SOUZA, D. H.; PEREIRA, L. L. \}

DOI: $10.12957 /$ REP.2020.47230

TRAD, L. A. B. Grupos focais: conceitos, procedimentos e reflexões baseadas em experiências com o uso da técnica em pesquisas de saúde. Physis, Rio de Janeiro, v. 19, n. 3, 2009.

WERNECK, J. Racismo institucional e saúde da população negra. Saúde Sociedade, São Paulo, v. 25, n. 3, 2016.

DOI: $10.12957 /$ rep.2020.47230

Recebido em 05 de julho de 2019.

Aprovado para publicação em 07 de novembro de 2019.

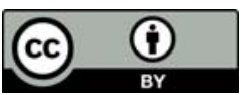

A Revista Em Pauta: Teoria Social e Realidade Contemporânea está licenciada com uma Licença Creative Commons Atribuição 4.0 Internacional. 